\title{
CIDADE MATARAZZO: FEITO POR QUEM
}

\section{“CIDADE MATARAZZO”: MADE BY WHOM}

\author{
A. Natália Hetem \& B. Ruth Verde Zein \\ PPGAU - UPM, Universidade Presbiteriana Mackenzie, Brasil \\ nathetem@gmail.com \\ rvzein@gmail.com
}

\begin{abstract}
RESUMO
O presente artigo trata da atual intervenção no quarteirão onde se situava o antigo Hospital Matarazzo na cidade de São Paulo, promovida pelo grupo francês Allard e com a participação de arquitetos internacionais, constando da construção de uma torre de arquitetura contemporânea junto ao complexo de edificações históricas e tombadas. Nele busca-se discutir as implicações que essa obra propõe em relação a questões patrimoniais envolvendo intervenções contemporâneas de arquitetura e urbanismo. Discute aspectos teóricos relativos à questão do patrimônio segundo autores clássicos e contemporâneos, no mundo e no Brasil, como base para um relato crítico sobre o processo em andamento do projeto e obra da "Cidade Matarazzo", um projeto majoritariamente voltado ao luxo mas que também envolve a criação de espaços públicos.
\end{abstract}

Palavras-chave: Patrimônio Histórico, Arquitetura Contemporânea, Urbanismo.

Linha de Investigação: 1: Cidade e projeto.

Tópico: projeto urbano e espaço público.

\begin{abstract}
This article is about the current intervention at the block where the old Hospital Matarazzo is in the city of São Paulo, promoted by the French group Allard, and with the participation of international architects at the construction of a new skyscraper with contemporary architecture next to a complex of old and listed buildings. This work aims the discussion that this construction brings related to heritage, contemporary intervention and urbanism. It will also be discussed heritage considering classic and contemporary authors, around the world and in Brazil, as a foundation to a critical report about the ongoing process of project and construction of "Cidade Matarazzo", a project mainly focused on luxury but which also involves the creation of public spaces.
\end{abstract}

Keywords: Heritage, Contemporary Architecture, Urbanism.

Research line: 1: City and project.

Topic: urban design and public space. 


\section{XII $\quad$ SÃOPAULO $15 \sim 17 \cdot$ LISBOA $25 \sim 26$ JUN 2020}

\section{Introdução}

Este trabalho tem como intuito considerar alguns aspectos relativos ao projeto "Cidade Matarazzo" que está sendo realizado na cidade de São Paulo (com término previsto para 2020 e 2021). A obra será tratada com maior profundidade no mestrado que a autora está desenvolvendo. Neste artigo serão feitas algumas considerações preliminares sobre esse empreendimento, relacionando-o com 0 tema das questões patrimoniais e urbanísticas. Será feito um breve panorama histórico sobre o conceito de patrimônio, a partir das principais cartas patrimoniais internacionais até as experiências contemporâneas e traz os pensadores do urbanismo Jane Jacobs e Jan Gehl. Serão consideradas as Cartas de Atenas de 1931 e a de Veneza de 1964, a questão da conservação integrada presente na Declaração de Amsterdã de 1975, bem como as questões concernentes aos instrumentos e políticas de intervenção em edifícios considerados patrimônio histórico, no Brasil.

O projeto "Cidade Matarazzo" é um empreendimento de grande porte promovido pelo Grupo Allard, de origem francês, capitaneado por Alexandre Allard. O projeto inclui a construção de uma nova torre corporativa no terreno onde se situa o conjunto de edificações históricas do antigo Hospital e Maternidade Matarazzo. Os novos projetos são de autoria do escritório do arquiteto francês Jean Nouvel, e os projetos de interiores é de responsabilidade do escritório do designer francês Phillippe Starck, havendo outros arquitetos franceses e brasileiros também envolvidos nesse processo (ficha técnica, fig. 1).

É uma obra recente próxima da Avenida Paulista, importante centro de serviços e comércios da cidade de São Paulo. A proposta foi anunciada como buscando ativar novos usos para região, considerando que se trata de amplo terreno que encontra-se sem uso ativo há algumas décadas, ela possui um caráter luxuoso no seu discurso, apresentação e linguagem arquitetônica, porém também se preocupa com questões públicas, que será o foco deste artigo. O empreendedor, Allard, tem em seu portfólio outras experiências voltadas para a renovação de edificações antigas, transformadas em hotéis e outros usos.

O artigo buscará realizar um breve histórico da questão patrimonial e de tombamento do conjunto existente, e dos novos projetos de intervenção propostos por esse empreendimento. Tem como objetivo fazer a análise crítica do projeto urbano vinculado ao empreendimento e discutir como este afetará a cidade, levando em consideração as questões patrimoniais. Irá também considerar como as mudanças radicais propostas nesse projeto podem ser consideradas, buscando compreender de que maneira a intenção de transformação do conjunto, proposta pelos empreendedores, afetará os seus usuários e seu entorno, com a proposta do túnel verde (que desvia a rota de carros da rua São Carlos do Pinhal e conecta o empreendimento com a Av. Paulista por um calçadão) e em que medida trará ou não benefícios reais e simbólicos para a população em geral. 


\section{XII $\mathbf{E}$ SÃOPAUL $15 \sim 17 \cdot$ LISBOA $25 \sim 26$ JUN 2020}

\begin{tabular}{|l|}
\hline Ficha técnica com os agentes envolvidos em cada projeto do complexo \\
\hline Jean Nouvel - Torre Mata Atlântica/Rosewood \\
\hline Philippe Starck - responsável pelo design de interiores do hotel \\
\hline Louis Benech - Paisagista \\
\hline Triptyque Architecture - "tropicalização" da Torre Mata Atlântica \\
\hline Rudy Ricciotti - Casa da Criatividade \\
\hline Adam Kurdahl (SPOL) - projetos executivos da área de "retail" \\
\hline Adriana Levisky - Reintegração Urbana \\
\hline Irmãos Campana - mobiliário urbano do mercado orgânico \\
\hline Informações gerais: \\
- Parque de 45.000m² ; \\
- $135.000 \mathrm{~m}^{2}$ de área construída; \\
- Catel 6 estrelas de $56.000 \mathrm{~m}^{2} ;$ \\
- 34 restaurantes; \\
- $28.500 \mathrm{~m}^{2}$ para vila de varejo; \\
- 2.200 vagas de estacionamento. \\
\hline
\end{tabular}

Fig. 1: Ficha técnica do projeto. Fonte: CIDADEMATARAZZO em L'Archictecture D’Aujourd'hui, Montpellier, França, p.1, 2019

\subsection{Métodos}

Os métodos utilizados para o desenvolvimento do artigo foram a leitura sobre teorias e teóricos de patrimônio e urbanismo, vistoria de processos no arquivo histórico e na gestão documental da cidade de São Paulo, além da busca por publicações sobre o assunto e visitas de campo.

\subsection{Resultados}

O resultado esperado é divulgar a obra que está sendo atualmente realizada, assim como apontar os pontos positivos e negativos da sua proposta de intervenção, considerando-se como ela afetará uma edificação tão antiga e significativa para a cidade, que é o Hospital Umberto I e Maternidade Matarazzo. Busca-se também pensar de que forma a abertura deste empreendimento comercial e voltado para o luxo irá afetar a cidade. E propõe-se discutir esse projeto após seu estudo pormenorizado e cotejamento com o conhecimento atual relativo às questões patrimoniais mais relevantes.

\section{Referencial Teórico}

A discussão sobre patrimônio histórico se consolida com a Carta de Atenas de 1931 e prossegue até atualmente, de maneira mais aberta e inclusiva. A Carta de Atenas de 1931 e a Carta de Veneza de 1964 que foi criada pelo segundo Congresso de Arquitetos e Especialistas em Edifícios Históricos, criadores 


\section{SÃOPAULO15 - $17 \cdot$ LISBOA $25 \sim 26$ JUN 2020}

também do ICOMOS (Conselho Internacional aos Monumentos Históricos e sítios) - são fundamentais para a discussão de patrimônio, já que são uns dos primeiros documentos a serem feitos do assunto na Europa. Cada uma foi feita em um tempo e leva em consideração o seu contexto, de cidades destruídas após as guerras mundiais.

A Carta de Atenas de 1931 trata da proteção dos monumentos, pensando em conservá-los e somente restaurar quando for indispensável.

A conferência recomenda respeitar, na construção dos edifícios, o caráter e a fisionomia das cidades, sobretudo na vizinhança dos monumentos antigos, cuja proximidade deve ser objeto de cuidados especiais. (Carta de Atenas, 1931)

O documento preza pelo emprego adequado de técnicas modernas, sem alterar o caráter da edificação a ser restaurada. Apresenta que deve haver interesse mundial público de salvaguardar os monumentos. Enfatiza a necessidade de uma boa educação para a população adquirir interesse pelo monumento. Impõe fazer registros e arquivos dos monumentos históricos, com informações e fotos.

A Carta de Veneza de 1964 é a carta internacional sobre conservação e restauração de monumentos e sítios. É utilizada até hoje como referência nos projetos de preservação e restauração pois se tornou o documento base do ICOMOS, não existe outra carta ou documento que a substitua. Segundo ela, as obras monumentais dos povos são testemunhos das tradições, são consideradas patrimônio comum pela humanidade, e esta deve preservá-las para as gerações futuras. Define monumento histórico como:

a criação arquitetônica isolada, bem como o sítio urbano ou rural que dá testemunho de uma civilização particular, de uma evolução significativa ou de um acontecimento histórico. Estende-se não só as grandes criações, mas também às obras modestas, que tenham adquirido, com o tempo, uma significação cultural. (Carta de Veneza, 1964)

A Carta trata a restauração e a conservação como disciplinas que utilizam colaboração de diferentes áreas e técnicas, com a finalidade de salvaguardar o patrimônio e o testemunho histórico. Em seu texto fica evidente que a conservação exige manutenção constante, é favorecida com uma destinação útil para a cidade, não se deve alterar as características do edifício, e o monumento é inseparável da sua história e testemunho do tempo no local inserido, é intolerável o seu deslocamento. Já a restauração é vista com caráter excepcional, tem como objetivo "conservar e revelar os valores estéticos e históricos do monumento e fundamenta-se no respeito ao material original e aos documentos autênticos" (Carta de Veneza, 1964). Essa ação é precedida de um estudo arqueológico do sítio, respeita as contribuições de épocas que o monumento sofreu, os 


\section{SÃO PAULO15 17 LISBOA $25 \sim 26$ JUN 2020}

elementos adicionais que substituem o que falta devem se integrar harmonicamente mas distinguindo-se do original e respeitando a edificação.

As cartas complementam as teorias já existentes sobre restauração e conservação, fornecendo recomendações e apoio ao profissional que atua na área.

Em 1975 foi definida a Declaração de Amsterdã, importante documento sobre patrimônio e que traz conceitos novos de gestão, como o de conservação integrada. Traz um sentido amplo de patrimônio, composto por conjuntos, bairros que tenham valor histórico e cultural, além dos bens isolados, e que é dever da população evitar a deterioração e proteger os bens. Tem o patrimônio como objetivo maior dos planejamentos da área urbana, que devem o considerar e o proteger. É preciso encorajar organizações privadas para contribuir no interesse público, é necessária a reprodução de relatórios periódicos do estado de conservação e do desenvolvimento do trabalho em cada país para que seja possível os conservar.

Introduz e aborda o conceito de conservação integrada para salvaguarda de patrimônio. A conservação integrada exige adaptações de medidas legislativas e administrativas para ter medidas financeiras apropriadas e convincentes, sendo cada estado responsável por seu próprio método e instrumento. Portanto ela é a base do funcionamento das políticas de salvaguarda, é um plano detalhado de como agir com as políticas públicas que deve ser elaborado pelo governo e instituições privadas, investidores.

Segundo a declaração, sem política de ação e proteção, e sem a conservação integrada não é possível se manter um patrimônio. A conservação do patrimônio deve ser incluída em programas de educação e desenvolvimento cultural para conhecimento do próprio à população. A participação popular deve, então, sempre estar presente.

Existem muitas teorias sobre restauração e conservação, uma complementando a outra e fornecendo diretrizes, mas e como agir? É necessário instrumentos e políticas, e isso que Castriota trata no seu livro "Patrimônio cultural: conceitos, políticas e instrumentos" no âmbito nacional e mais contemporâneo.

O autor aborda o patrimônio ambiental urbano, que é a renovação e transformação da cidade, acompanhando o desenvolvimento da sociedade e o governo orientando para que a paisagem urbana evolua de maneira equilibrada. Se pensa no todo, e como as coisas se relacionam, não só no objeto isolado. $\mathrm{A}$ intenção é preservar o equilíbrio da paisagem.

Segundo o autor, no Brasil não se aceita o conceito contemporâneo e ampliado de patrimônio, logo não se tem um tipo definido de intervenção. Se há três modelos teóricos a partir dos termos: preservação, conservação e reabilitação, cada um parte de uma concepção de patrimônio e estabelece um objeto, pressupõe um marco legal e atores diferentes. 


\section{SÃOPAULO15 $17 \cdot$ LISBOA $25 \sim 26$ JUN 2020}

No modelo de conservação o conceito de patrimônio é ampliado, temos o patrimônio ambiental urbano, que tem valor cultural e ambiental e valoriza a cultura em um sentido amplo. Os tipos de objetos são os grupos de edificações históricas, paisagens urbanas e espaço público. O marco legal é a área de conservação, com ação do Estado e parte integral do planejamento urbano, envolve, planejadores urbanos além dos arquitetos e historiadores. A conservação integrada é um dos objetivos centrais do planejamento urbano e regional e envolve gestão e planejamento, é a integração entre preservação do patrimônio e planejamento urbano, resultado da ação técnica de restauro e das funções apropriadas para integrar o patrimônio no ambiente de vida dos cidadãos.

É importante para o artigo trazer o pensamento de dois pensadores do urbanismo, Jane Jacobs e Jan Gehl, junto do histórico de patrimônio.

Jacobs (2000) acredita que, para uma cidade ser bem sucedida nos seus bairros é preciso ter diversidade, com mistura de usos, pois uma grande variedade deixa a paisagem urbana viva. Na sua visão, para se gerar diversidade, é preciso ter um distrito que atenda mais de uma função principal, quadras curtas, distrito com boa porcentagem de edifícios antigos e em estados de conservação variados para gerar renda e densidade alta. A presença de edifícios antigos é importante pois eles têm valor menor do que se construir um novo. $O$ que torna dinâmico um centro é a mistura de edifícios novos e antigos.

Gehl (2010), propõe a retomada da dimensão e da escala humana nas cidades para fornecer maior qualidade de vida a sua população. Gehl descende da atuação reformadora de Jacobs, como o de ter distâncias curtas para se andar mais a pé, criar espaços públicos mais atrativos e variedade de funções e usos ao longo da cidade. Enfatiza o retorno do pedestre para a cidade, que perdeu o seu espaço com a chegada da indústria automobilística.

Para Gehl (2010), é preciso reforçar a questão do pedestre para se ter uma cidade viva, segura, sustentável e saudável. Cidade viva, pois com os pedestres haveria maior uso dos espaços públicos, retomada das zonas de transição (espaços que se tornam agradáveis de transitar e caminhar) e mais vitalidade e tranquilidade. Retoma-se a questão de caminhar para chegar ao destino, utilizando a cidade de uma forma mais dinâmica e concentrada. Cidade segura também conta com a ajuda do pedestre, pois quanto mais pessoas na rua, mais vigiada ela fica, e portanto quanto mais segura e agradável de passear, mais viva ela se torna. A cidade sustentável com relação ao pedestre é que ele contribui para reduzir a emissão de carbono e reduz a poluição gerada por automóveis, indústrias e edifícios, tendo mais pessoas caminhando ou pedalando pela cidade, o que a torna melhor para viver. 


\section{SÃOPAULO15 $17 \cdot$ LISBOA $25 \sim 26$ JUN 2020}

Seminário Internacional de Investigação em Urbanismo

Seminario Internacional de Investigación en Urbanismo

\section{Sobre o empreendimento}

Considerando esse breve panorama sobre algumas importantes questões relativas aos conceitos de patrimônio e urbanismo propomos realizar uma análise do projeto "Cidade Matarazzo", com foco em como essa proposta se relaciona e trata as questões debatidas, buscando entender que qualidades e problemas ele poderá gerar.

O projeto está localizado no terreno que o Hospital Matarazzo se situa. Próximo à Avenida Paulista, no quadrilátero formado pelas ruas Itapeva, Pamplona, São Carlos do Pinhal e Alameda Rio Claro (Fig. 2).

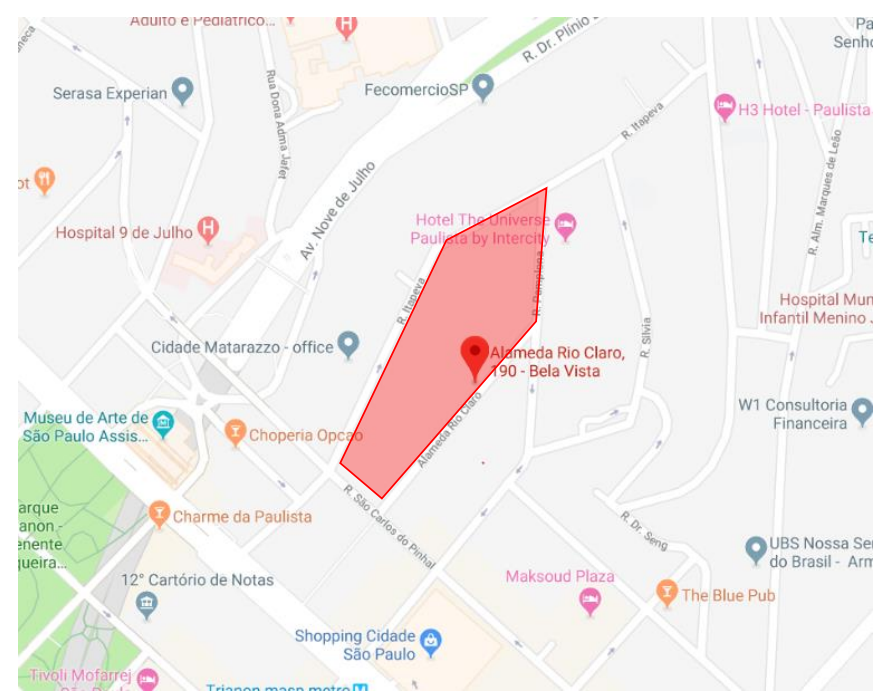

Fig. 2: Imagem da localização do terreno do conjunto. Fonte: Google Maps

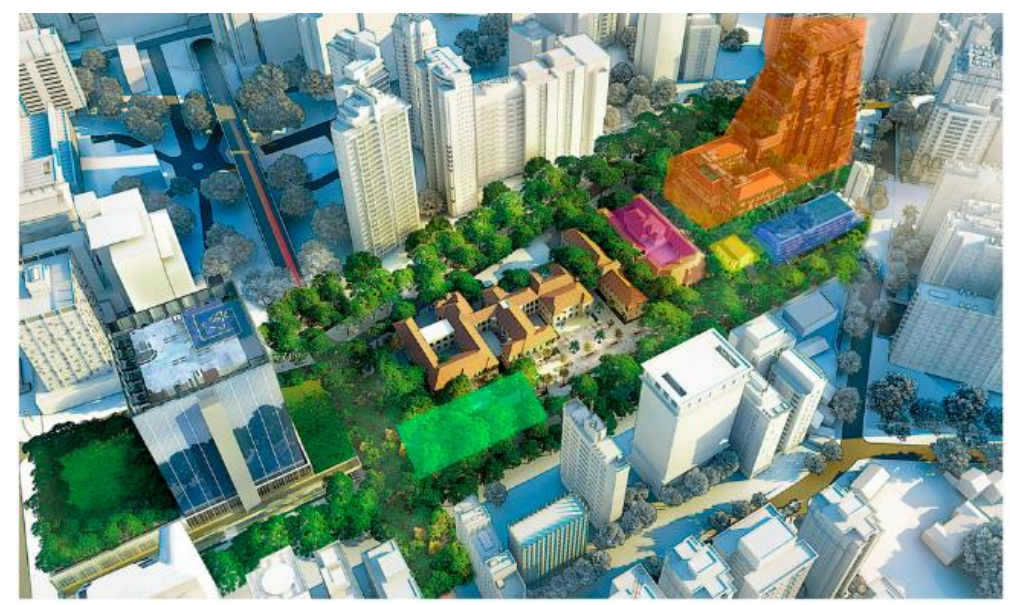

\section{IMPLANTAÇÃO DO EMPREENDIMENTO}

\section{LEGENDA}

ETORRE ROSEWOOD

CASA DA CRIATIVIDADE

CAPELA

- CENTRO COMERCIAL

MERCADO ORGÂNICO

Fig. 3: Implantação do complexo. Fonte: https://www.cidadematarazzo.com.br/empreendimento-implantao 


\section{XII $\quad$ SÃO PAULO15 $17 \cdot$ LISBOA $25 \sim 26$ JUN 2020}

Seminário Internacional de Investigação em Urbanismo

Seminario Internacional de Investigación en Urbanismo

O antigo complexo hospitalar se transformará em um centro comercial, cultural e, principalmente, hoteleiro, voltado para uma determinada elite (Fig. 3). Será um ambiente multifuncional que pretende atender certas demandas da região.

\subsection{Histórico do conjunto de edificações}

Para salvaguardar o conjunto do Hospital, prevenindo sua destruição, o Hospital foi tombado pelo CONDEPHAAT (Conselho de Defesa do Patrimônio Histórico, Arqueológico, Artístico e Turístico) com a Resolução SC 29/86 em 1986. Na resolução consta que o Hospital e Maternidade Umberto I (ex Hospital Matarazzo) é representativo das instituições imigrantes da cidade de São Paulo, exerceu papel de destaque no atendimento médico, como local de estudo e prática profissional, sendo pioneiro no desenvolvimento de atividades hospitalares na cidade e pelo seu conjunto arquitetônico harmonioso. Foi então considerado importante histórica e arquitetonicamente e, portanto, o seu conjunto arquitetônico foi tombado.

Após alguns anos de discussão, em que algumas partes envolvidas entendiam como demasiado rigorosa a resolução de tombamento, em 2014, houve uma revisão do tombamento estabelecido anteriormente. O CONPRESP estabelece a Resolução N 05, que considera o processo de tombamento anterior e o conjunto como Zona Especial de Preservação Cultural segundo a lei n 13.885 de 1975 e então resolve tombar o conjunto arquitetônico edificado do antigo Hospital Umberto I (Fig. 4).

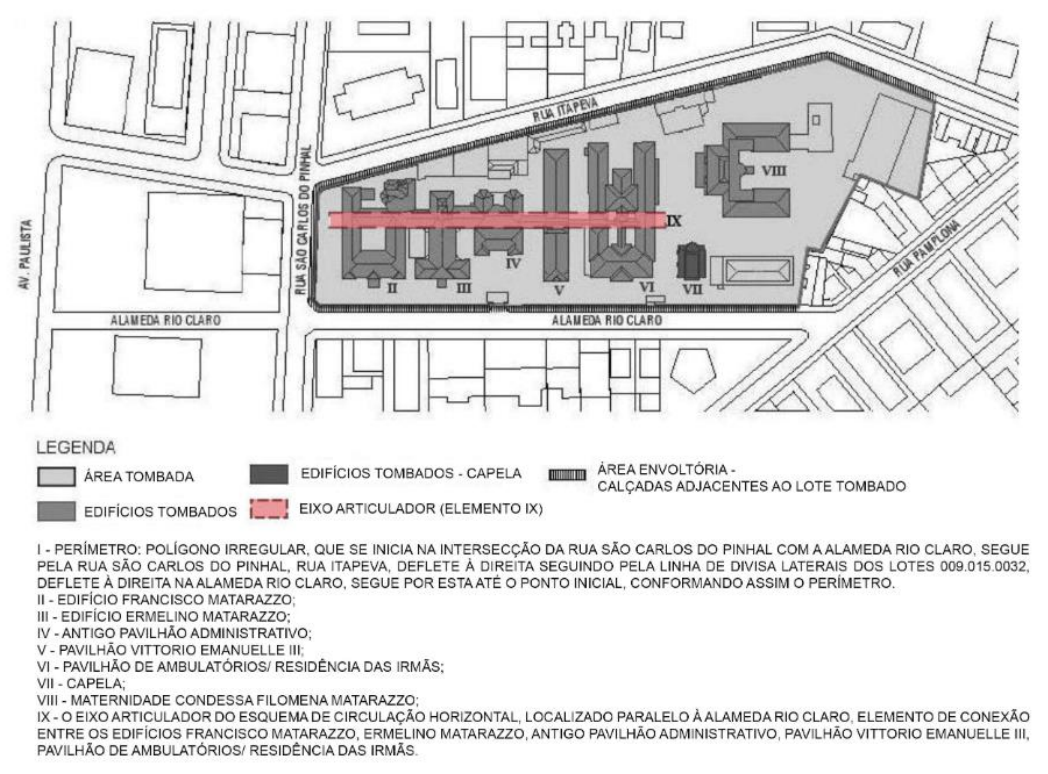

Fig. 4: Mapa do perímetro de tombamento da resolução 5/2014 pelo CONPRESP.

Fonte: https://www.prefeitura.sp.gov.br/cidade/upload/Mapa0514PDF_1432740866.pdf 


\section{SÃOPAULO15 $17 \cdot$ LISBOA $25 \sim 26$ JUN 2020}

\subsection{Histórico do investidor}

O grupo Allard é conhecido pela compra e reforma de antigas edificações e hotéis em Paris, França, transformando-as em edificações de serviços com infraestrutura luxuosa. Tem como filosofia de investimento adquirir locais, sociedades e projetos com forte dimensão cultural.

Segundo o site do empreendimento ${ }^{1}$, o Grupo Allard teve seu interesse pelo complexo do Hospital Matarazzo, e adquirido o imóvel em 2008, por seu caráter potencial em termos de investimento em cultura e arte, a ser combinado com serviços, tais como um hotel e instalações comerciais de luxo, para geração de renda ao conjunto.

\subsection{Setor hoteleiro do empreendimento}

O projeto prevê a participação de importantes figuras do mundo artístico, do design e da arquitetura internacional para sua execução, se tornando em um grande complexo pensado para a elite, ou seja, minoria da cidade. Segundo os empreendedores:

O Cidade Matarazzo oferece uma inovadora e requintada combinação de hospitalidade, varejo, gastronomia, cultura e entretenimento, no maior parque privado de São Paulo, com árvores centenárias e flora tropical. Um refúgio de paz no meio da selva de concreto, a poucos metros da Avenida Paulista. (CIDADEMATARAZZO, fevereiro de 2020, disponível em: https://www.cidadematarazzo.com.br/\#empreendimento)

Os edifícios históricos tombados serão restaurados e preservados, incluindo a Capela. Ao lado da antiga edificação da maternidade será construída uma nova torre projetada pelo arquiteto francês Jean Nouvel, abrigando um grande hotel de luxo, 6 estrelas, da empresa Rosewood Hotels\&Resorts.

O projeto de Jean Nouvel integra a estética dos edifícios históricos com a arquitetura contemporânea, criando um símbolo para a cidade que se perpetuará no futuro das novas gerações. (CIDADEMATARAZZO, fevereiro de 2020, disponível em: https://www.cidadematarazzo.com.br/hotel-fachada)

Segundo os autores, a torre Rosewood tem como proposta se mesclar na paisagem e dar continuidade ao "parque Matarazzo", por isso a grande presença de árvores e vegetação nas suas fachadas e interiores, além do emprego de materiais como a madeira, o metal com aspecto de madeira e o concreto (Fig. 5). Segundo Jean Nouvel, a ideia de colocar as árvores da torre veio após sua visita à maternidade e ao complexo

\footnotetext{
${ }^{1}$ Segundo o site da Cidade Matarazzo, na parte de conceito e patrimônio. (Disponível em: https://www.cidadematarazzo.com.br/conceito-patrimnio acesso 05 de fevereiro de 2020)
} 


\section{SÃOPAULO15 - $17 \cdot$ LISBOA $25 \sim 26$ JUN 2020}

histórico, onde percebeu que havia muita vegetação e um clima próprio, levantando a sugestão de integrar os dois locais com a presença da vegetação na torre também contrastando com as outras torres na Avenida Paulista. (L'Archictecture D'Aujourd'hui, Montpellier, França, p.24-27, 2019)

Além desse grande complexo de luxo, haverá uma área para comércio e será implantado um grande jardim, com as árvores brasileiras mais comuns e famosas. O jardim inspirado na Mata Atlântica seria, segundo o arquiteto, uma maneira de evidenciar a brasilidade, como vista e conhecida pelos estrangeiros, uma brasilidade genérica e generalizada. E neste jardim ocorrerá um mercado orgânico e a conexão com a Av.Paulista.

O empreendimento propõe um calçadão que conectará os dois, como solução eles pretendem criar um túnel verde sob a rua São Carlos do Pinhal.

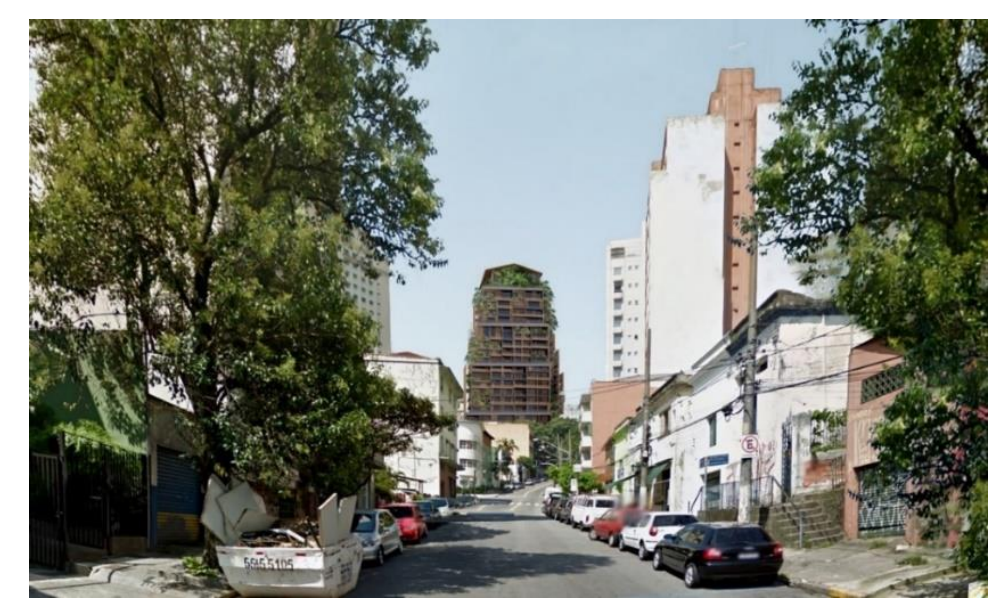

Fig. 5: Imagem renderizada da Torre inserida na paisagem da cidade. Fonte: http://www.jeannouvel.com/projets/torre-rosewood/

\subsection{A intervenção urbana}

A maior intervenção urbana se dá por um túnel verde na rua São Carlos do Pinhal (Fig. 6 e 7), chamado "Boulevard da Diversidade". A ideia seria de maneira a facilitar o acesso dos pedestres ao complexo e seu jardim, desviando a rota de carros para o subsolo. A proposta envolveria uma grande obra de engenharia e tinha previsão de conclusão para 2022; mas a ideia vem sofrendo forte oposição dos comerciantes estabelecidos nas ruas locais, e por isso foi postergada. 


\section{XII $\mathbf{E}$ SÃOPAUL $15 \sim 17 \cdot$ LISBOA $25 \sim 26$ JUN 2020}

Seminário Internacional de Investigação em Urbanismo

Seminario Internacional de Investigación en Urbanismo

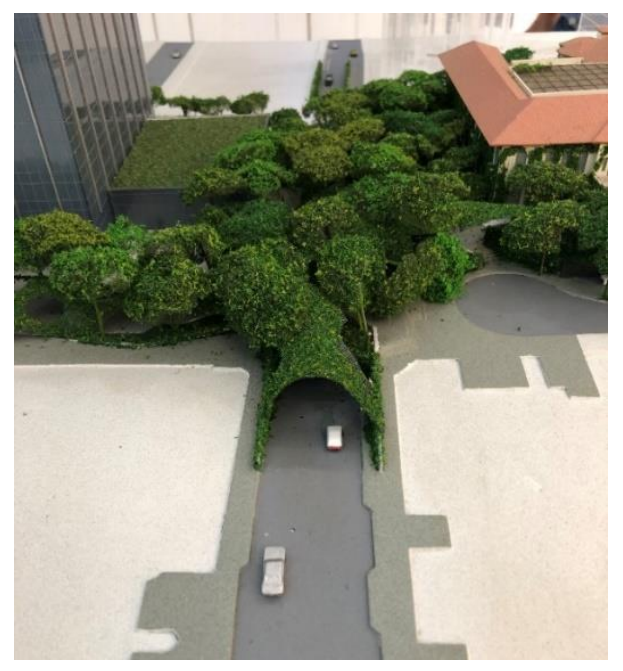

Fig. 6: maquete do showroom do "Boulevard da Diversidade. Fonte: Showroom Cidade Matarazzo, foto de Natália Hetem (outubro de 2019)

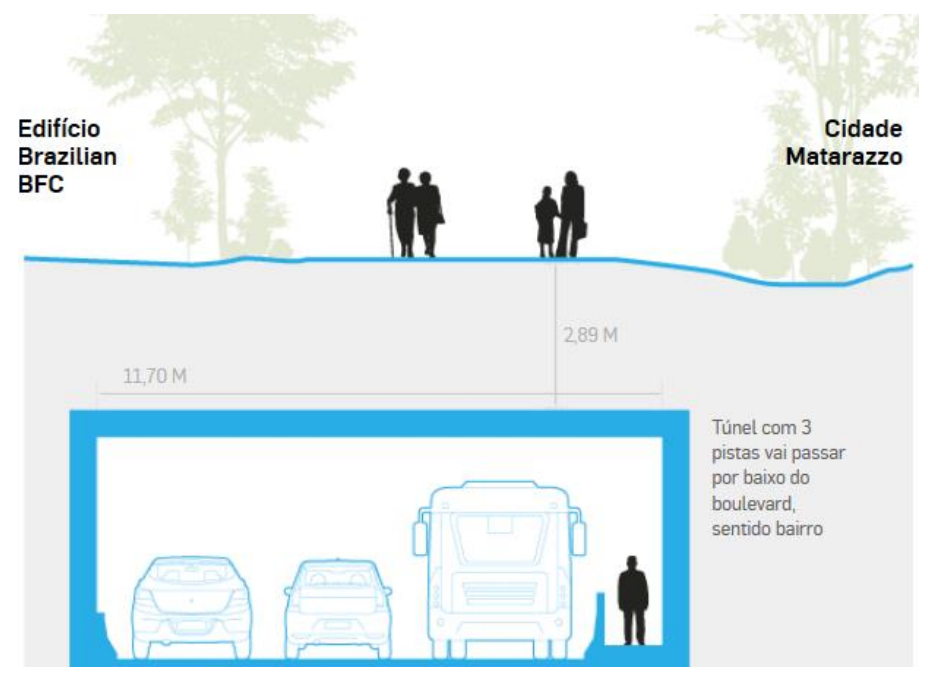

Fig. 7: corte esquemático do túnel. Fonte: Estadão (https://sao-paulo.estadao.com.br/noticias/geral,sp-megacomplexo-de-luxo-emantigo-hospital-sera-aberto-em-maio-na-bela-vista,70003024352 acesso setembro de 2019)

No nível da rua seria então criado o "Boulevard da Diversidade", projeto da arquiteta e urbanista Adriana Levisky. Segundo o plano de trabalho do acordo de cooperação do Boulevard da Diversidade, o projeto pretende transformar o espaço urbano e os hábitos das pessoas que circulam a região. É proposto, além do túnel, uma requalificação urbana da alameda das flores (rua que encontra à Av. Paulista, fornecendo então 


\section{XII $\quad$ SÃO PAULO $15 \sim 17 \cdot$ LISBOA $25 \sim 26$ JUN 2020 \\ Seminário Internacional de Seminario Internacional de Investigação em Urbanismo Investigación en Urbanismo}

um fácil acesso ao empreendimento), com o objetivo de ampliar o espaço público e tornar este trecho aberto ao público (Fig. 8).

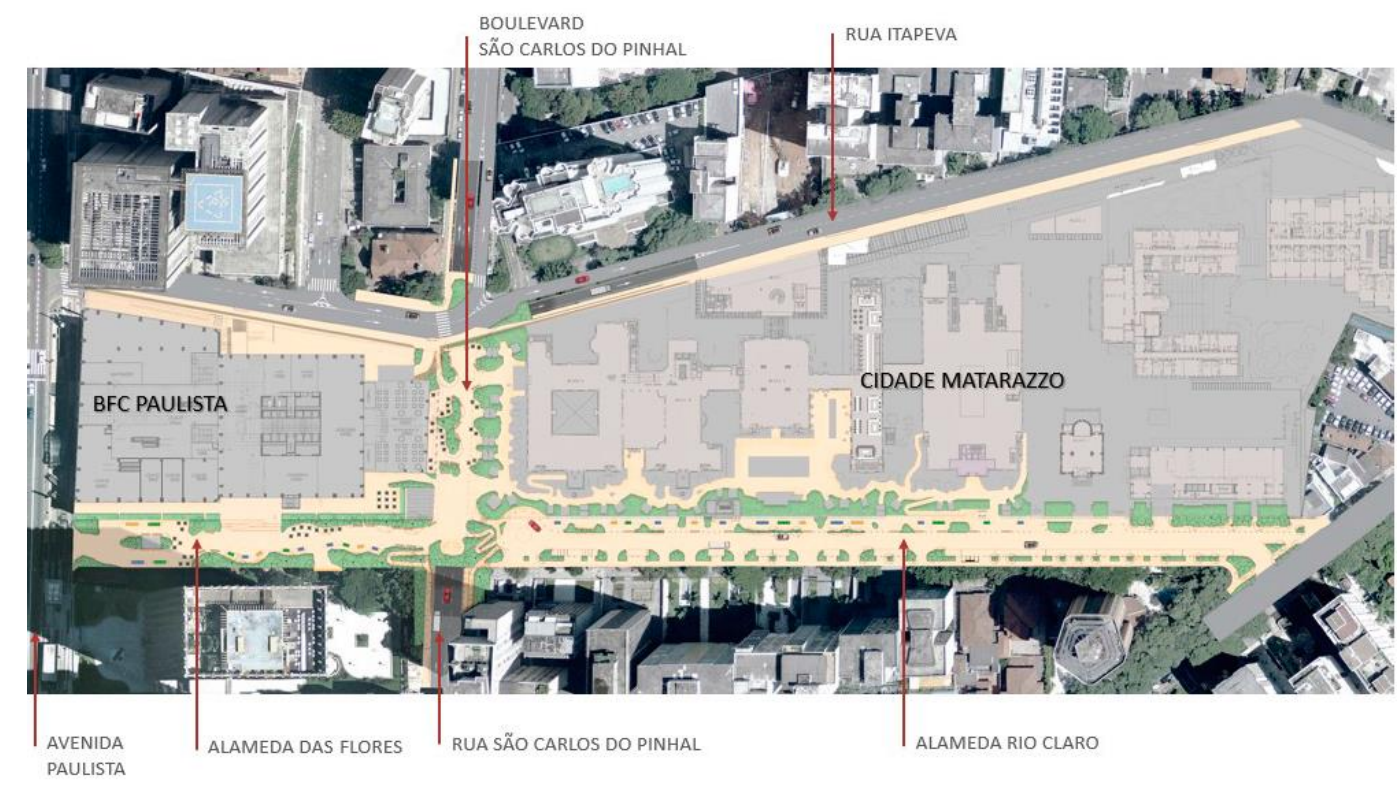

Fig. 8: Implantação do Boulevard da Diversidade. Fonte: Plano de Trabalho de Acordo de Cooperação - Anexo V do Edital n1-2019, pág.3 (https://www.prefeitura.sp.gov.br/cidade/secretarias/upload/Anexo\%20V\%20do\%20Edital\%20n\%C2\%BA\%201-2019.pdf Acesso: abril de 2020)

\section{O debate em torno da "Cidade Matarazzo"}

A partir desse breve histórico sobre o local e considerando o referencial teórico, pode-se considerar que o empreendimento proposto, a ser implantado ao lado de edificações de valor patrimonial e histórico, suscita a possibilidade de algumas análises, questionamentos e críticas.

Nos projetos de intervenção em patrimônio histórico edificado, em um geral, é possível perceber a influência e presença norteadora dos conceitos presentes nas cartas internacionais. Isso também acontece em algumas partes do caso em estudo, a "Cidade Matarazzo". Na "Cidade Matarazzo" é possível ver aplicação de alguns preceitos da Carta de Veneza, como estudo do local e de viabilidade, e a presença da restauração nas edificações tombadas. Entretanto, não é proposta uma conservação integrada, já que o empreendimento está sendo inteiramente realizado com verba privada. É a maior obra privada de revitalização já feita na cidade de São Paulo, sem ajuda de qualquer recurso público.

Ainda assim, todas as mudanças feitas no complexo foram registradas, relatadas e divulgadas no Diário Oficial da Cidade de São Paulo, o que está de acordo com o que diz a Declaração de Amsterdã de 1975. Ao longo da duração das obras também foram realizados eventos fechados e abertos para a população, 


\section{SÃOPAULO15 $17 \cdot$ LISBOA $25 \sim 26$ JUN 2020}

permitindo a visita e uma maior tomada de conhecimento acerca do novo projeto, e foram feitas algumas ações visando relembrar o valor histórico do hospital e maternidade. Esse foi o ponto de maior contato entre a população e a obra, visto não ter havido participação popular no desenvolvimento dos projetos novos do conjunto. A decisão unilateral pela característica de alto luxo do restante do empreendimento evidencia a questão da elitização daquele local.

Segundo Castriota (2009, pág.87), "qualquer intervenção sobre o patrimônio como uma ação sobre o presente é uma proposta para o futuro", e alerta sobre as questões envolvidas em casos de intervenções em edificações históricas e de cunho patrimonial. O caso da "Cidade Matarazzo" segue o modelo de conservação descrito por Castriota, inclusive no âmbito de patrimônio ambiental urbano por envolver um conjunto de edificações significativas para a história da cidade. Por outro lado, o projeto é também invasivo na questão da infraestrutura urbana, já que vai alterar o fluxo de uma avenida paralela à avenida Paulista. Uma região que tem grande movimento e circulação de automóveis que durante a construção do túnel ficará ainda mais intensa. Os automóveis serão desviados, já que o projeto, com essa medida, privilegia o pedestre, o que coloca em prática o pensamento de grandes escritores do urbanismo, como Jan Gehl e Jane Jacobs.

Com certeza a "Cidade Matarazzo" terá um grande impacto, e talvez, como querem seus empreendedores, a proposta esteja pensando o que seria uma cidade para o futuro. O empreendimento considera, ainda que parcialmente, o respeito aos aspectos históricos daquele lugar, e embora de forma secundária, inclui a presença de alguns poucos profissionais brasileiros, junto com os profissionais internacionais. Ainda assim, a "brasilidade" é uma questão inúmeras vezes repetida nos textos de descrição do projeto, o qual afetará usuários e população em geral por sua grandiosidade, provavelmente acarretando em algum grau de reconhecimento mundial, graças à presença das grandes figuras internacionais (e talvez menos, pela "brasilidade" em si mesma, aliás, conceito de difícil qualificação da situação concreta desse local e o acontecimento estar vinculado aos tempos atuais).

O projeto do Grupo Allard pensa alguns dos itens principais de conservação e preservação do patrimônio; ao mesmo tempo intervém de maneira brutal na paisagem, através da imponente presença da nova torre proposta, ainda em construção (2020) e do túnel a ser construído, que mudará de maneira intensa o trânsito no local durante sua construção e depois. Pode-se dizer que nele está sendo pensado conjuntamente o espaço histórico e os novos espaços.

Trata-se portanto de um projeto de grandes dimensões, no qual a participação da prefeitura e de órgãos públicos se restringiu somente ao fornecimento de dados históricos, e na análise e aprovação dos projetos. Não houve participação da população da cidade, apesar de ter havido um acesso muito restrito ao público, 


\section{XII $\quad$ SÃO PAULO $15 \sim 17 \cdot$ LISBOA $25 \sim 26$ JUN 2020}

para as pessoas poderem entrar nas antigas edificações do Hospital, que aconteceu apenas por um dia, ou em datas isoladas, como nas iniciativas da Paulista Cultural.

\section{Considerações Finais}

Com o estudo sobre patrimônio e as informações coletadas até o momento (janeiro 2020) sobre o empreendimento da "Cidade Matarazzo" é possível perceber que, embora realizado em São Paulo, atende a lógicas comerciais e de empreendimento internacionais, com grande presença de capitais europeus no projeto e obra.

A região da Av. Paulista, destinada desde sua inauguração para a implantação de casarões para uma elite formada por imigrantes enriquecidos por empreendimentos comerciais e industriais, tornou-se, mais ao final do século 20, um centro urbano mais comercial e mais popular. O empreendimento proposto, pelas suas características, sugere uma retomada da elitização dessa área. O discurso de luxo, beleza, integração é muito atraente para todos, mas da maneira como o projeto arquitetônico e urbano está sendo proposto, deverá trazer retorno principalmente para uma minoria, que de fato poderá ter acesso e desfrutar de tudo isso. Há chances muito altas de que esse empreendimento venha a se tornar um ambiente altamente elitizado - e com uma grande participação de uma elite internacional - mesmo que seja possível acessar o complexo para a parte cultural. Depois de anos fechado, seu acesso acabará sendo mais restrito do que os discursos organizados pelos empreendedores podem dar a entender. Possivelmente, as camadas de população não elitizada da cidade - a maioria de nós - talvez não se sinta à vontade para visitar e fazer parte desta nova história do complexo, caracterizado por áreas de luxo para hotel e lojas, a serem, provavelmente, vigiadas e controladas. O discurso de preservação da história e cultural é muito bonito, mas algo que não é respeitado, de maneira indireta e irônica, é o próprio patrimônio, já que a nova torre, por ser mais alta que o gabarito das edificações históricas e por ser diferente das edificações ao redor, se destacará na paisagem, minimizando e secundarizando os edifícios históricos existentes. Segundo as cartas anteriormente mencionadas, em princípio qualquer nova intervenção junto a obras de valor histórico deveriam ser neutras e não chamarem mais atenção que os edifícios originais. Neste caso, a nova edificação ganhará mais importância e terá mais impacto urbano do que as edificações históricas existentes, pelo menos no que se refere ao visual, ainda que o complexo histórico esteja sendo restaurado e também receberá um novo uso.

O empreendimento da "Cidade Matarazzo" segue vários conceitos apresentados por Gehl e Jacobs, pretendem valorizar o pedestre, acumular funções em um só local e criar um ambiente diversificado. Gehl e Jacobs pensaram nisso para uma cidade de uma maneira geral, onde se cada bairro atendesse a esses conceitos, a cidade se tornaria mais agradável para habitar. Não é à toa que o empreendimento se chama 


\section{SÃO PAULO15 17 LISBOA $25 \sim 26$ JUN 2020}

"Cidade Matarazzo", pois de fato o que será construído no local se tornará uma espécie de pequena cidade, com vários serviços diferentes a disposição dos usuários que a frequentarem.

No país em que vivemos, atualmente, é muito difícil detectar ações privadas ou públicas que favoreçam a integração de camadas sociais, com raras exceções. Provavelmente não será nesse empreendimento de altíssimo padrão, batizado como "Cidade Matarazzo", que isso irá acontecer. Entretanto, será preciso aguardar a sua inauguração para realmente ter a certeza sobre seu verdadeiro destino, e se esse conjunto será assimilado, ou não, pela população paulistana.

\section{Referências}

CARTA DE ATENAS - 1931. INSTITUTO DO PATRIMÔNIO HISTÓRICO E ARTÍSTICO NACIONAL (IPHAN). Disponível em:

http://portal.jphan.gov.br/uploads/ckfinder/arquivos/Carta\%20de\%20Atenas\%201931.pdf Acesso: 20 de março de 2018.

CARTA DE VENEZA - 1964. INSTITUTO DO PATRIMÔNIO HISTÓRICO E ARTÍSTICO NACIONAL (IPHAN). Disponível em: http://portal.jphan.gov.br/uploads/ckfinder/arquivos/Carta\%20de\%20Veneza\%201964.pdf Acesso: 14 de março de 2018.

CASTRIOTA, Leonardo B. (2009). Patrimônio Cultural. Conceitos, políticas e instrumentos. São Paulo: Annablume; Belo Horizonte: IEDS.

CIDADEMATARAZZO. Disponível em: http://www.cidadematarazzo.com.br/site/pt Acesso: 08 de maio de 2019.

CIDADEMATARAZZO. Disponível em: https://www.cidadematarazzo.com.br/transformadores Acesso: 28 de Agosto de 2019.

CIDADEMATARAZZO. Urban Recycling. L'Archictecture D'Aujoud'hui. Montpellier, France, HorsSérie/Projets, 2019.

DECLARAÇÃO DE AMSTERDÃ - 1975. INSTITUTO DO PATRIMÔNIO HISTÓRICO E ARTíSTICO NACIONAL (IPHAN). Disponivel em: http://portal.iphan.gov.br/uploads/ckfinder/arquivos/Declaracao\%20de\%20Amsterda\%CC\%83\%201975.pdf Acesso: 20 de março de 2019

GEHL, Jan. (2010) Cidades para pessoas. São Paulo: Perspectiva (2 $2^{\mathrm{a}}$ edição). JACOBS, Jane. (2011). Morte e vida de grandes cidades. São Paulo: Editora WMFmartinsfontes, (coleção cidades $3^{\text {a }}$ edição).

JEANNOUVEL. Projeto da Torre Rosewood. Disponível em: http://www.jeannouvel.com/projets/torrerosewood/ Acesso: 14 de maio de 2019. 


\section{SÃOPAULO15 - $17 \cdot$ LISBOA $25 \sim 26$ JUN 2020}

MENGUE. Priscila. Boulevard Verde na região da Paulista. Disponível em: https://www.mobilize.org.br/noticias/11802/sao-paulo-tera-um-boulevard-verde-na-regiao-dapaulista.html?fbclid=IwAR1NKKjafkf1tcV4Zg0cpBt_rjEI5Z4fYW2LUjVQoheg3KPKyftcTqwvOcY Acesso: 27 de setembro de 2019.

L'ARCHITECTURE D'AUJOURD'HUI. Actualités: Jean Nouvel: “j'ai imagine l'antithèse des tours de São Paulo. Disponível em: http://www.larchitecturedaujourdhui.fr/58131/ Acesso: 27 de maio de 2019

SÃOPAULO. Prefeitura do Estado de São Paulo. Plano de trabalho. Acordo de cooperação Boulevard da Diversidade.

https://www.prefeitura.sp.gov.br/cidade/secretarias/upload/Anexo\%20V\%20do\%20Edital\%20n\%C2\%BA\%201 -2019.pdf Acesso: 14 de abril de 2020.

SÃOPAULO. Prefeitura do Estado de São Paulo. RESOLUÇÃO SC29/86 DE 1986. Disponível em: https://www.prefeitura.sp.gov.br/cidade/upload/fe856_RES.\%20SC\%20N\%2029\%20\%20Hospital\%20e\%20Maternidade\%20Umberto\%20I.pdf Acesso: 09 de maio de 2019.

SÃOPAULO. Prefeitura do Estado de São Paulo. RESOLUÇÃO N 05 DE 2014. Disponível em: www.prefeitura.sp.gov.br/cidade/upload/Re0514TexofficioConEdAntigoHospitalUmbertoIDOC_1400874834.d ocx Acesso: 09 de maio de 2019.

SÃOPAULO. Prefeitura do Estado de São Paulo. RESOLUÇÃO N 05 DE 2014 - MAPA. Disponível em: https://www.prefeitura.sp.gov.br/cidade/upload/Mapa0514PDF_1432740866.pdf Acesso: 09 de maio de 2019. 